\title{
6. RELATIONSHIP OF RESISTIVITY, VELOCITY, AND POROSITY FOR BASALTS FROM DOWNHOLE WELL-LOGGING MEASUREMENTS IN HOLE 418A 1
}

\author{
Roy Wilkens and David Schultz, Earth Resources Laboratory, Massachusetts Institute of Technology, \\ Cambridge, Massachusetts ${ }^{2}$ \\ and \\ Richard Carlson, Department of Geophysics and Geodynamics Research Program, Texas A\&M University, \\ College Station, Texas ${ }^{3}$
}

\begin{abstract}
The analysis of geophysical well-logging data collected during ODP Leg 102 in Cretaceous oceanic crust at the southern end of the Bermuda Rise provides insight into the porosity structure of oceanic crust. The data are studied solely in terms of their well log behavior rather than in terms of the units previously defined by inspection of the core. This approach subdivides the hole on the basis of the porosity structure of the column. A new variable, $\Delta \mathrm{V} / \Phi$, is introduced and defined. Incorporating both velocity and porosity, $\Delta V / \Phi$ addresses changes in velocity due to differences in porosity and pore structure. Based upon the relationships between velocity and porosity, the basalts are divided into three behavioral types. Although the three behavior types represent an arbitrary division of what is actually a data continuum, the behaviors can be related to rock units or distinctive micro- and macrostructural attributes. Type I behavior (high velocity and low $\Delta \mathrm{V} / \Phi$ ) represents high-porosity basalts with subspherically shaped pores, whereas type II basalts (high velocity and high $\Delta \mathrm{V} / \Phi$ ) are more likely to have flat cracks permeating the rock. Type III basalts appear to be pillow basalts with low velocities and high porosities.
\end{abstract}

\section{INTRODUCTION}

Geophysical well logging has long been used in the oil industry to delineate individual sedimentary units and to correlate those units from one borehole to another in the same stratigraphic sequence. Many years of data collection from thousands of wells provide the basis for the identification of the combinations of properties that distinguish rock types such as limestone, sandstone, and shale from one another. The interpretive tools employed are largely empirical and in that sense tell us more about "average" sandstones and limestones and may often provide misleading results.

The problem facing students of the oceanic crust is somewhat different. We already know that what has been drilled, by and large, is basalt. Even with the small data set available today, it is possible to tell the difference between basalt and sediment or, for that matter, basalt and many of the sedimentary rocks considered by industry. It may be a very long time, however, before enough well-logging data from the ocean crust have been collected to allow for the development of reliable empirical relationships that can illuminate the nature of the crustal structure sampled by the borehole. The problem is easily seen by examining the range of logging properties of the basaltic units identified from recovered core by the shipboard scientists of Legs 5153 (table 8, Shipboard Scientific Party, 1986). The properties of pillow or massive units do not appear to occupy distinct ranges of porosity and velocity (or electrical resistivity, not shown) but overlap one another (Fig. 1).

\footnotetext{
${ }^{1}$ Salisbury, M. H., Scott, J. H., et al., 1988. Proc. ODP, Sci. Results, 102: College Station, TX (Ocean Drilling Program).

2 Addresses: Earth Resources Laboratory, Department of Earth, Atmospheric and Planetary Sciences, Massachusetts Institute of Technology, Cambridge, MA 02142; (Wilkens, present address) Hawaii Institute of Geophysics, 2525 Correa Road, Honolulu, HI 96822; (Schultz, present address) Department of Atmospheric Sciences, AK-40, University of Washington, Seattle, WA 98195.

3 Address: Department of Geophysics and Geodynamics Research Program, Texas A\&M University, College Station, TX 77843.
}

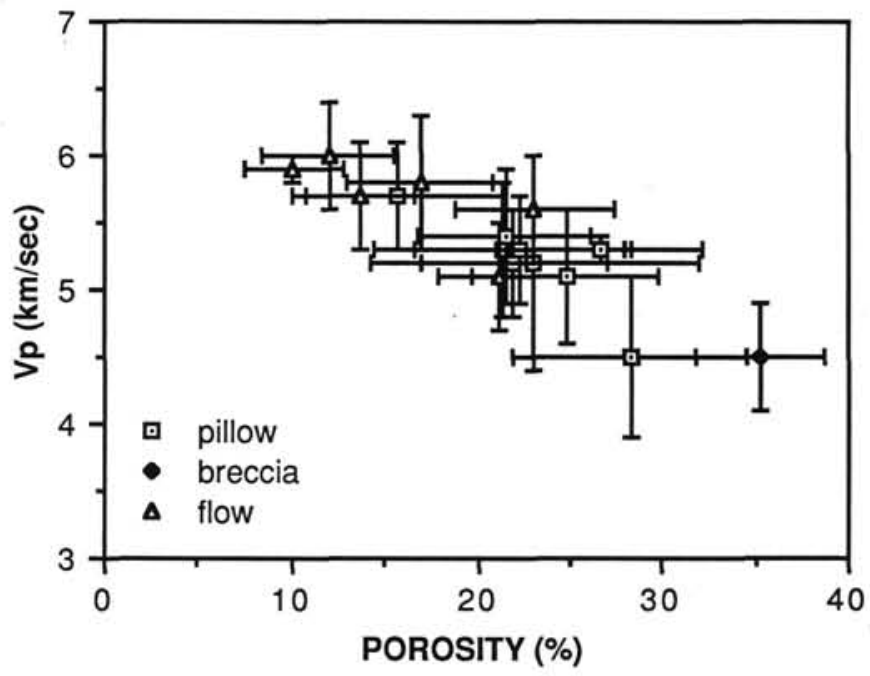

Figure 1. Properties of Hole 418A basement units from well logs (table 8, Shipboard Scientific Party, 1986). Different types of basalts have overlapping ranges.

In this study, we examine the well-logging data from Hole $418 \mathrm{~A}$ in the light of what we know of rock behavior from the large body of laboratory and theoretical work already in existence. Rather than describe the properties of units defined by core description, we will subdivide the logging results based on well $\log$ behavior. We adopt this approach because we are not concerned with the velocity or porosity ranges of a particular pillow unit identified within some depth range, but rather with what those velocities and porosities tell us about the in-situ state of the oceanic crust. We then suggest how these behaviors may be interpreted in terms of pore distribution and connectivity.

A better understanding of well-logging data from the oceans may eventually lead to a change in ocean-drilling strategies. It is interesting to note that coring is rare in industry drilling opera- 
tions. This is because it is costly and time consuming. Particularly in small area studies, replacing coring with logging at some sites might increase the number of holes that can be drilled and consequently expand the amount of available data.

\section{DATA}

Depth profiles of porosity, resistivity, velocity, and several derived parameters discussed subsequently are shown in Figure 2. All data considered in this report were collected during logging operations on ODP Leg 102. We have limited the analysis to data from depths of $600 \mathrm{~m}$ below seafloor (mbsf) to the bottom of the logged interval (780 mbsf) in order to avoid the upper levels of the hole, where alteration of the basalts tends to change matrix parameters such as velocity and density. The logging values have been averaged over $1 \mathrm{~m}$, calculated at $0.5-\mathrm{m}$ intervals. This process smooths the traces and helps to reduce scatter in cross correlations between logs made on different lowerings, where slight offsets in true depth may occur. The sacrifice in resolution is not significant because most of the logging tools measure formation properties over distances on the order of a meter. A complete description of logging operations during Leg 102 is contained in Salisbury, Scott, et al. (1986). The following contains brief descriptions of the primary logs and the procedures used to derive several calculated parameters.

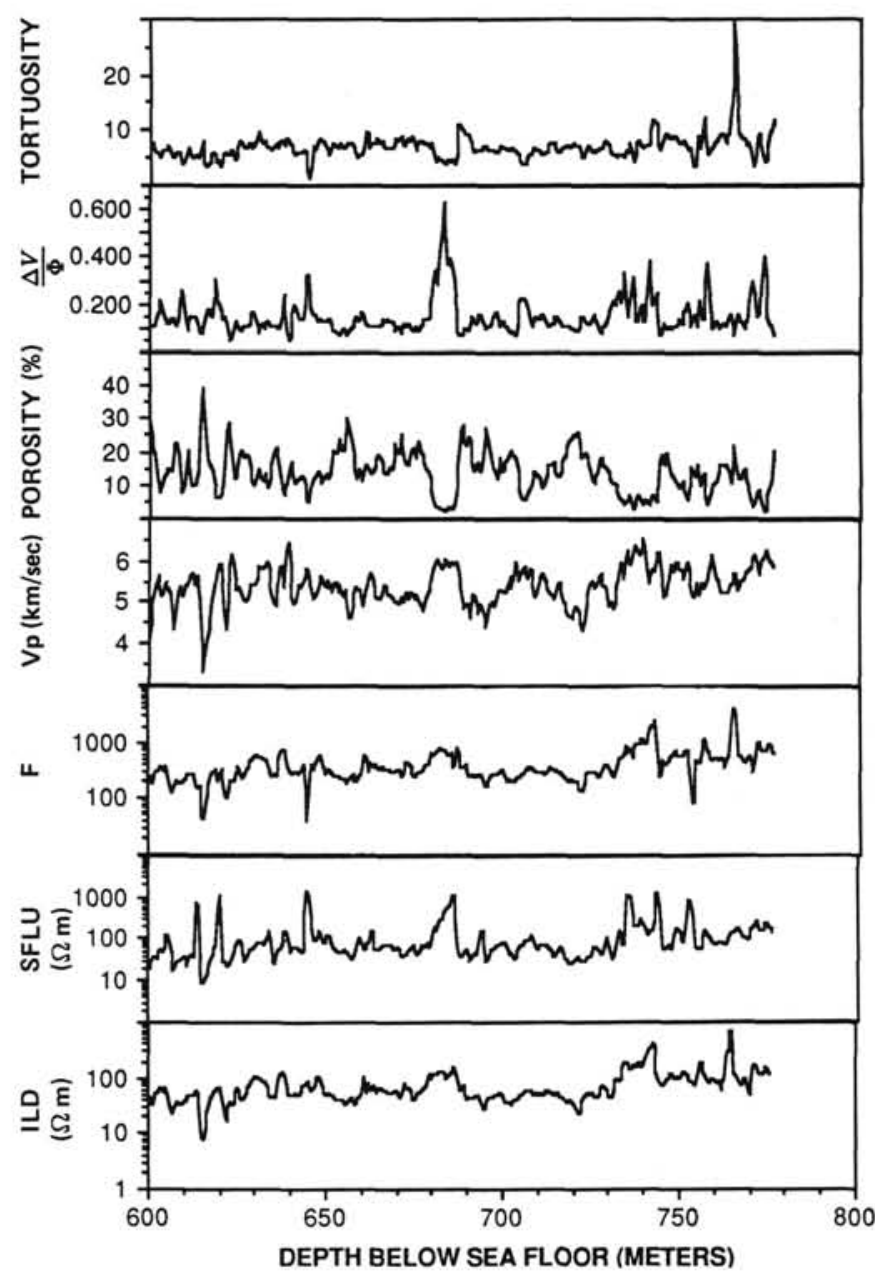

Figure 2. Well logs from Hole $418 \mathrm{~A}$. Tortuosity and $\Delta V / \Phi$ are calculated from logging values as discussed in text. Porosity has been corrected by $6 \%$.

\section{Porosity}

Formation porosity was measured using the dual-porosity compensated neutron tool (CNTG). The original data were corrected for borehole conditions using standard industry calibration procedures (Serra, 1984; Broglia and Moos, this volume). None of the corrected porosities (NPHIC), however, were less than $6 \%$, even in the most massive, competent basalts. This relationship has been seen at other oceanic logging sites (Cann and Von Herzen, 1983; Kirkpatrick, 1979). We follow their procedure in assuming that some of the lowest NPHIC values must have been recorded in massive basalts with near-zero porosity. The porosity value used in this study is NPHIC minus $6 \%$. This correction does not change the relative shape of the porosity log but merely shifts it toward more realistic values of porosity, especially in the lowest porosity rocks (Broglia and Moos, this volume).

\section{Resistivity and Formation Factor}

Several different resistivity measurements were recorded at Hole 418A using the dual induction (DIL) tool. The deep induction log (ILD) was chosen on the basis of our desire to eliminate many of the borehole effects seen in logs with shallower depths of investigation. A cross-correlation of ILD and the spherically focused $\log$ (SFLU) (Fig. 3) suggests that the majority of the points lie near the line SFLU = ILD. However, there are a significant number of points that have SFLU values substantially larger than the corresponding ILD values. These points coincide with peaks in the SFLU log that are not seen in the ILD trace (Fig. 2). We hypothesize that this is due to two factors: (1) the ILD is less sensitive than the SFLU to near-borehole disturbance and (2) because the SFLU investigates a smaller volume of rock, it has a greater chance of measuring the resistivity of crack-free (higher resistivity) intervals.

The formation factor $(F)$ is defined as:

$$
F=\frac{\mathrm{R}_{\text {rock }}}{\mathrm{R}_{\text {sw }}},
$$

where $R_{\text {rock }}$ is the rock resistivity and $R_{\text {sw }}$ is the pore-fluid (seawater) resistivity (Archie, 1942). $F$ has been found to be con-

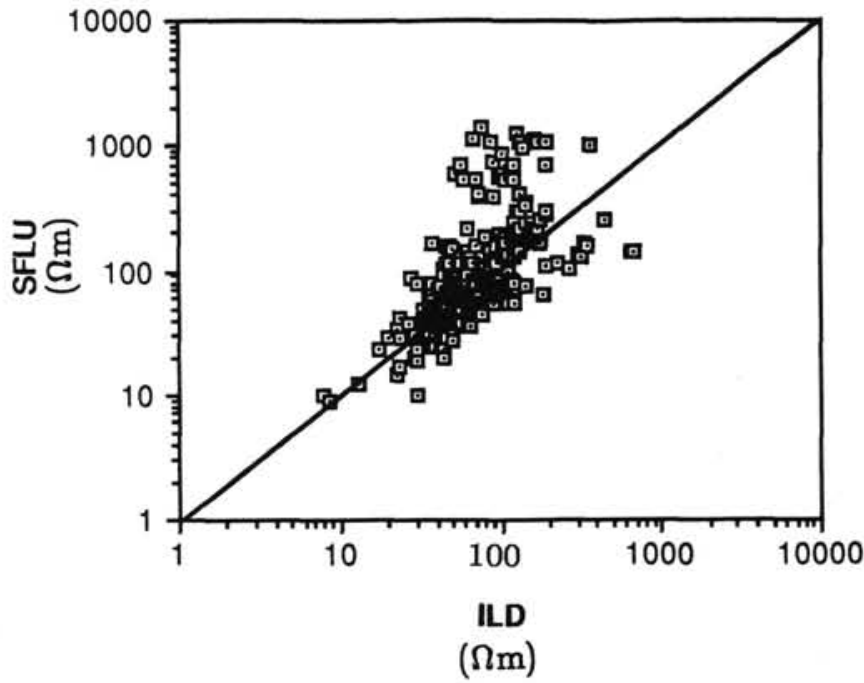

Figure 3. Deep induction (ILD) log values vs. spherically focused (SFLU) $\log$ values. SFLU appears more sensitive to borehole irregularities. 
stant for individual rocks over a wide range of pore-fluid resistivities and thus is useful in comparing resistivity data from formations with differing environments. Our calculation assumes that the pore fluid in the basalt is seawater (Kirkpatrick, 1979; Cann and Von Herzen, 1983) and applies a correction for borehole temperature. Given the borehole temperature gradient of $0.024^{\circ} \mathrm{C} / \mathrm{m}$ within the basaltic section and the temperature at the basalt/sediment contact of $19.2^{\circ} \mathrm{C}$ (Shipboard Scientific Party, 1986), we calculate the temperature profile in the basement:

$$
\mathrm{T}=19.2+0.024(\mathrm{DBSF}-325),
$$

where DBSF is the depth (mbsf), 325 is the sediment thickness (m), and $\mathrm{T}$ is ${ }^{\circ} \mathrm{C}$. The empirical relationship describing the conductivity of seawater as a function of temperature is given as

$$
\mathrm{R}_{\mathrm{sw}}{ }^{-1}=\sigma_{\mathrm{sw}}=3+0.1 \mathrm{~T},
$$

where $\mathrm{R}_{\mathrm{sw}}$ is in ohm-m, $\sigma_{\mathrm{sw}}$ is in mhos $/ \mathrm{m}$, and $\mathrm{T}$ is ${ }^{\circ} \mathrm{C}$ (Horne and Frysinger, 1963; Bradshaw and Schleicher, 1980). Combining (1), (2), and (3), we obtain an expression for the conversion of resistivity to formation factor at Hole $418 \mathrm{~A}$ :

$$
F=\text { ILD } \times(4.14+0.0024 \mathrm{DBSF})
$$

\section{Tortuosity}

Tortuosity $(\tau)$ is defined as the square root of the product of porosity and $F$ (Ward and Fraser, 1967).

$$
\tau=\sqrt{F \phi}
$$

It represents the length of an equivalent pore with a circular cross section and volume equal to total porosity. We may use $\tau$ as an index of porosity structure; the larger the value, the more convoluted the pore paths.

\section{Velocity}

The long-spaced sonic (LSS) tool recorded compressionalwave velocity $\left(\mathrm{V}_{p}\right)$ downhole. The tool records the time difference between the arrival of an acoustic signal at two receivers spaced $2 \mathrm{ft}$ apart. Two sources, placed 8 and $10 \mathrm{ft}$ from the near receiver, sample the formation at shallower and deeper levels. We have chosen to use data from the longer travel path, although the two logs are almost identical.

\section{The Variable $\Delta \mathrm{V} / \Phi$}

In order to better understand velocity relationships between different parts of the borehole, we compare all of them to a standard, nonporous basalt. It is convenient to introduce a variable we will call $\Delta V / \Phi$; in some respects it resembles the derivative of velocity with respect to porosity. It is defined as follows:

$$
\frac{\Delta \mathrm{V}}{\Phi}=\frac{\mathrm{V}-\mathrm{V}_{\mathrm{m}}}{0-\Phi}
$$

where $\mathrm{V}_{\mathrm{m}}(\mathrm{km} / \mathrm{s})$ is a constant equal to the velocity of the matrix of the basalt (to be discussed later), 0 is the porosity of the matrix, and $\mathrm{V}(\mathrm{km} / \mathrm{s})$ and $\Phi(\%)$ are the velocity and porosity from the logs. $\Delta V / \Phi$ is a variable that compares measurements of both the velocity and the porosity of a rock compared to some measure independent of both these terms $\left(V_{m}\right)$. There is a large volume of laboratory and theoretical work (Nur and Simmons, 1969; Kuster and Toksöz, 1974; O'Connell and Budiansky, 1974; Cheng and Toksöz, 1979; Wilkens et al., 1986) that illustrates the complexity of the true relationship between velocity and porosity in rocks. Velocities depend on matrix properties as well as on both total porosity and on the shapes and distribution of the pores in a sampled volume. Spherical pores reduce velocity much less than flat cracks with the same volume. Therefore, for a given porosity, the difference between the matrix velocity and the log velocity for a sample with spherical pores (small $\Delta \mathrm{V} / \Phi$ ) will be less than that for cracked samples (large $\Delta V / \Phi)$. Thus, $\Delta V / \Phi$ may help us to better understand something about pore configuration or shape and can be viewed as the velocity equivalent of electrical measurement criteria such as $\tau$ or $F$.

In this report we use a value of $7.1 \mathrm{~km} / \mathrm{s}$ for the velocity of the matrix basalt. Although this value depends to a small degree on the mineral assemblage, glass content, degree of metamorphism, and other factors, we will take it to be a constant for fresh oceanic basalt. High-pressure measurements of the velocity of low-porosity samples taken from the recovered core (Christensen et al., 1980) suggest a value of $7.1 \mathrm{~km} / \mathrm{s}$ for a basalt with zero (or near zero) porosity. The high-pressure value $(600 \mathrm{MPa})$ is chosen particularly because we believe that the application of confining pressure will close many of the microcracks in the sample (Birch, 1960). This is a distinctly different approach than that taken by previous authors (Salisbury et al., 1985; Kirkpatrick, 1979). Earlier studies have cited sample velocity values measured at simulated in-situ pressures. Differences between laboratory and borehole determinations in the previous studies are attributed to cracks or pores that exist on a scale larger than that of a laboratory sample. When there is agreement between both measurements, the sample is then taken to be representative of the formation as a whole. Although this is a useful approach, it does not explain the pore characteristics of the sample itself and their attendant effect on the velocity of the sample. The causes of velocity differences between laboratory samples and borehole measurements are precisely the same as velocity differences between an uncracked, nonporous sample and a porous sample measured at simulated in-situ pressure. The scale difference between the laboratory and the field is an artificial distinction based solely on the size of hydrostatic pressure vessels, not on some structural parameter intrinsic to the formation or emplacement of oceanic basalts. By applying a matrix velocity of $7.1 \mathrm{~km} / \mathrm{s}$ directly to the well-logging results we address all scales of inhomogeneity at once and attempt to elucidate the pore structure of the basaltic crust solely from true in-situ measurements.

\section{DISCUSSION}

\section{Porosity-Velocity}

The relationship between velocity (or slowness) and porosity as measured by logging in the basalts of Hole 418A is not simple. This can be seen in the plot of velocity vs. porosity shown in Figure 4. For a porosity of $10 \%$, velocities range between slightly less than 5 to $6.25 \mathrm{~km} / \mathrm{s}-\mathrm{a}$ variation of $20 \%$. Furthermore, a linear regression of these two variables yields an intercept of approximately $6.3 \mathrm{~km} / \mathrm{s}$. This value would represent the velocity of a basalt with zero porosity if there were a linear relationship between velocity and porosity. The value is plainly too low, considering the fact that some of the velocities actually exceed $6.3 \mathrm{~km} / \mathrm{s}$ and still exhibit a nonzero porosity. Ambiguities arise because pore shape is an important factor in determining porosity-velocity relationships (Kuster and Toksöz, 1974; O'Connell and Budiansky, 1974). There is no denying the first-order reduction of velocity with increasing porosity seen in Figure 4. However, for two pores with the same volume, the more oblate (flatter) pore will decrease velocity by a larger amount.

Lines of constant $\Delta \mathrm{V} / \Phi$ (assuming a matrix velocity of $7.1 \mathrm{~km} / \mathrm{s}$ ) can be drawn on the graph of velocity vs. porosity (Fig. 4). The data field cuts across the lines of $\Delta V / \Phi$, with the 


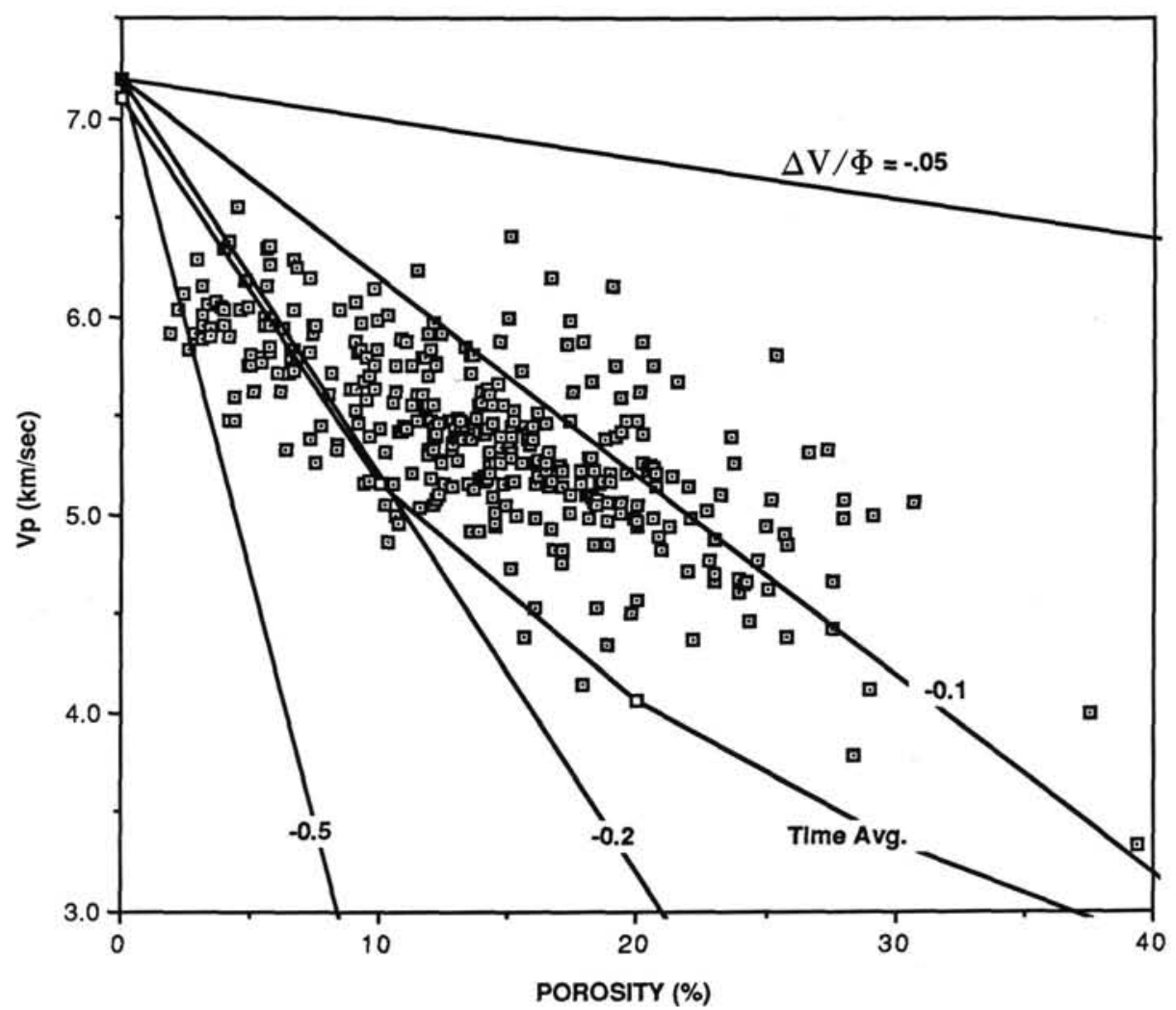

Figure 4. Porosity vs. velocity with time-average relation of Wyllie et al. (1958) and lines of constant $\Delta \mathrm{V} / \Phi$.

lower-porosity data exhibiting greater values of $\Delta V / \Phi$ than those with higher porosities. We have also included a time-average line (Wyllie et al., 1958) in Figure 4 for the appropriate matrix velocity and a fluid velocity of $1.5 \mathrm{~km} / \mathrm{s}$. The time-average equation is not a good fit to the data, although it does exhibit the same behavior relative to $\Delta V / \Phi$ that is seen in the data; as porosity increases, $\Delta \mathrm{V} / \Phi$ decreases.

The relationship between porosity and $\Delta V / \Phi$ is illustrated in Figure 5. Low porosities exhibit a wide range of $\Delta V / \Phi$ values, whereas greater porosities are restricted to low $\Delta V / \Phi$. The rea-

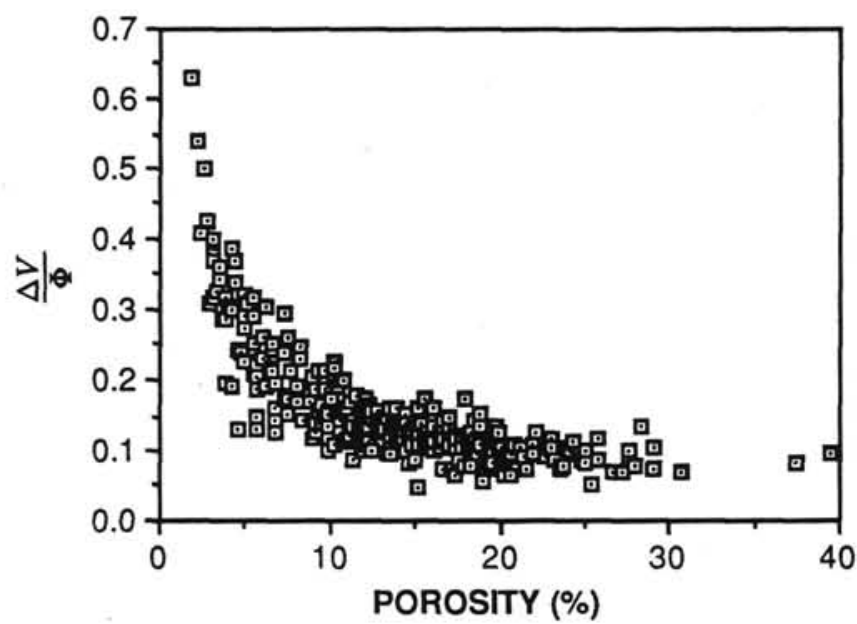

Figure 5 . Porosity vs. $\Delta \mathrm{V} / \Phi$. High-porosity basalts always have low values of $\Delta V / \Phi$, whereas low-porosity basalts exhibit a range of values. son for this trend lies in the relationship between length and volume for relatively flat vs. nearly spherical pores. A flat crack may be considered to be an almost two dimensional object; that is, its volume will depend on some characteristic length $\mathrm{L}$ to the second power. A sphere, however, will increase its volume as $\mathrm{L}$ cubed. This suggests that as the number of pores (and total porosity) increases in a rock, an increasingly greater volume of those pores will be within subspherical cavities. Because subspherical pores have less of an effect on velocity than cracks (for a given volume) and subspherical pores are volumetrically more abundant than cracks at higher porosities, values of $\Delta V / \Phi$ normally decrease as total porosity increases.

It is also useful to consider the relationship between $\Delta V / \Phi$ and velocity (Fig. 6). For high velocities, $\Delta V / \Phi$ has a broad range, with the range narrowing as velocity decreases. The figure suggests a large amount of scatter in the data, but if we divide the data into three arbitrary behavioral types (Table 1 and Fig. 7) it can be seen that behavior is regular (i.e., discrete depth intervals are described by a single cross-plot sector). Behavior type I includes data that lie within the range $\mathrm{V}_{p}>5.25 \mathrm{~km} / \mathrm{s}$ and $\Delta \mathrm{V} / \Phi<0.15$. Type II limits are $\mathrm{V}_{p}>5.25 \mathrm{~km} / \mathrm{s}$ and $\Delta \mathrm{V} / \Phi$ $>0.15$. Type III consists of data with $\mathrm{V}_{p}<5.25 \mathrm{~km} / \mathrm{s}$, regardless of the value of $\Delta \mathrm{V} / \Phi$. Type III behavior is the most simple to explain. Low velocity corresponds to high porosity (Fig. 4), which will almost certainly mean a low $\Delta V / \Phi$ based on the geometrical volume abundance arguments (Fig. 5). Consequently, we can expect these data (based on choices from the core description) to be pillow basalts or breccias with high porosities. Types I and II both have high velocities, which suggests lower porosities. The effect of the porosity on velocity is different, however, for the two data fields.

In the "end-member" sense, we might think of type I as spherical porosity and type II as crack porosity. In the data, 


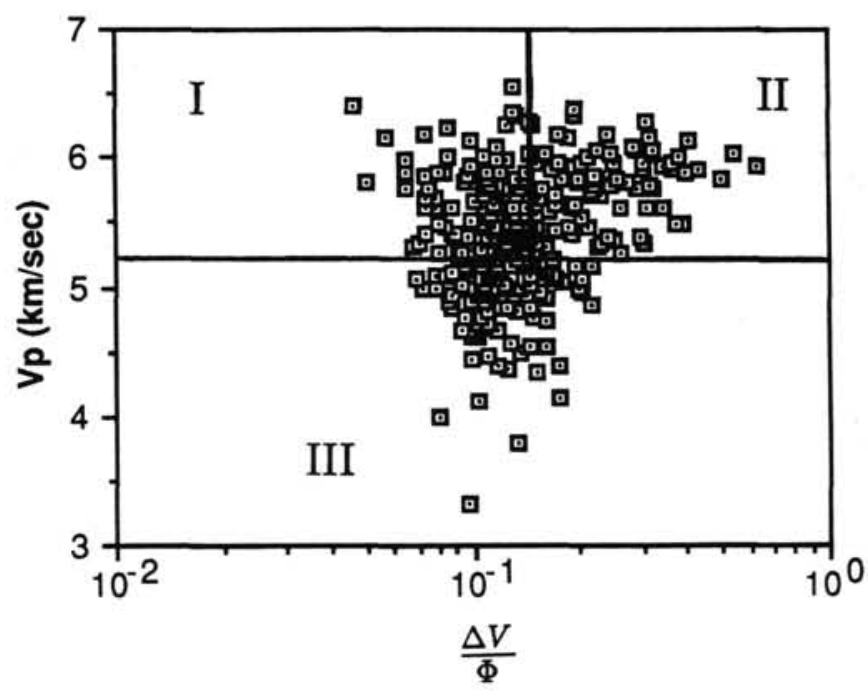

Figure 6. $\Delta V / \Phi$ vs. velocity. Groups I, II, and III represent different behavior types discussed in text.

Table 1. Classification of basalt types in Hole 418A.

\begin{tabular}{lccl}
\hline & $\begin{array}{c}\mathrm{Vp} \\
(\mathrm{km} / \mathrm{s})\end{array}$ & $\Delta \mathrm{V} / \Phi$ & \multicolumn{1}{c}{ Comments } \\
Type & & \multicolumn{1}{c}{} \\
\hline I & $\geq 5.25$ & $\leq 0.15$ & Vesicular basalts \\
II & $\geq 5.25$ & $>0.15$ & Fractured, massive basalts \\
III & $<5.25$ & all & Pillow basalts \\
\hline
\end{tabular}

type I represents something like a vesicular basalt, with much of the volume of the pore space taken up in rounded pores. Type II, vesicular or not, must contain a relatively larger volume of cracks than type I.

We have plotted the three behavioral types vs. depth in Figure 7 and indicated the unit definitions from core described during Legs 52 and 53; the subdivisions of Unit 13 are based on logs (Broglia and Moos, this volume). Whereas there is certainly no direct correlation between the units and the types, we do see that the behavior is nonrandom, that is, it is consistent over intervals down the hole. In particular, the two units described from the core as massive (Units 10 and 12) are reasonably well defined by type II behavior. Subunit 13B, defined as massive by Broglia and Moos (this volume), also fits into type II classification. Type changes between I and III represent changes in velocity for the most part, because the samples with $\mathrm{V}_{p}<5.25 \mathrm{~km} / \mathrm{s}$ do not exhibit a wide range of $\Delta V / \Phi$.

\section{Porosity-Formation Factor}

Tortuosity computed from porosity and formation factor is a value much like $\Delta V / \Phi$ in that $\tau$ is an indicator of the extent of complication of pore structure. The relationship between porosity, $F$, and $\tau$ is illustrated in a plot of porosity vs. $F$ with lines of $\tau$ superimposed on the data (Fig. 8). The pattern seen in Figure 8 is a result of the same geometrical complications and variety of pore structures that affected velocity-porosity relations (Fig. 4). Low porosity corresponds to somewhat lower values of $\tau$ (most values between 4 and 8 ), whereas higher values of porosity appear to have a wider range of $\tau$. Type II behavior from the velocity $-\Delta V / \Phi$ plot (Fig. 6) exhibits the lowest porosity for a given $F$, whereas type III behavior tends toward higher porosities for the same formation factor.

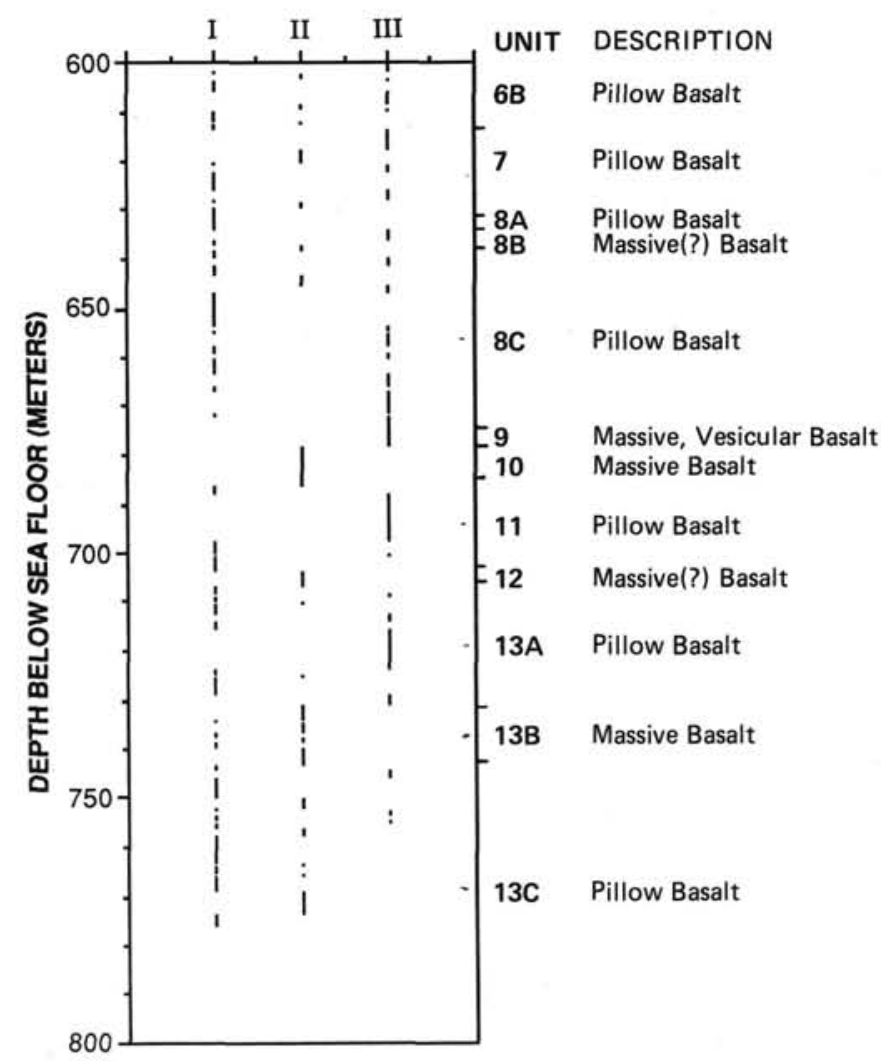

Figure 7. Basalt types I, II, and III as a function of depth; unit descriptions from Legs 52 and 53 and Broglia and Moos (this volume). Massive Units 10 and 12 and Subunit 13B appear to correlate well with type II behavior.

The $\tau$-porosity relationship of type II data in Figure 8 lends support to our speculation about the nature of the basalts exhibiting this behavior. High velocity and high $\Delta V / \Phi$ suggest a cracked, massive unit. These intervals have low values of $\tau$, indicating relatively simple pore pathways, and high values of $F$ can be explained by the low overall porosity. Type I data overlap type III data for porosity ranging from $10 \%$ to $20 \%$, whereas type I tends toward greater values of $F$ (and $\tau$ ) than type III for a given value of porosity. This may represent a somewhat smaller mean size distribution for pores in type I, or it may simply mean that the pores in the type I basalts are not as well connected as those of type III.

We have shown that both $\tau$ and $\Delta \mathrm{V} / \Phi$ are related to pore structure. These two parameters are plotted against one another in Figure 9. The importance of the figure, however, is not the trend but rather, where the data lie and what that implies about pore structure. Segments of the borehole with large values of $\Delta \mathrm{V} / \Phi$ and low $\tau$ are explainable as massive basalt units with throughgoing cracks. Greater $\tau$ and lower $\Delta V / \Phi$ suggest an increase in isolated, subspherical pore space.

\section{CONCLUSIONS}

The results of this study suggest that oceanic basalts may be described and analyzed in terms of properties measured by logs. This is an alternative to describing the logging response of units that have been already been distinguished by observation of the recovered core. As more data become available, it is possible that the study of these behaviors may eventually result in a greater understanding of the geophysical significance of the logs, 


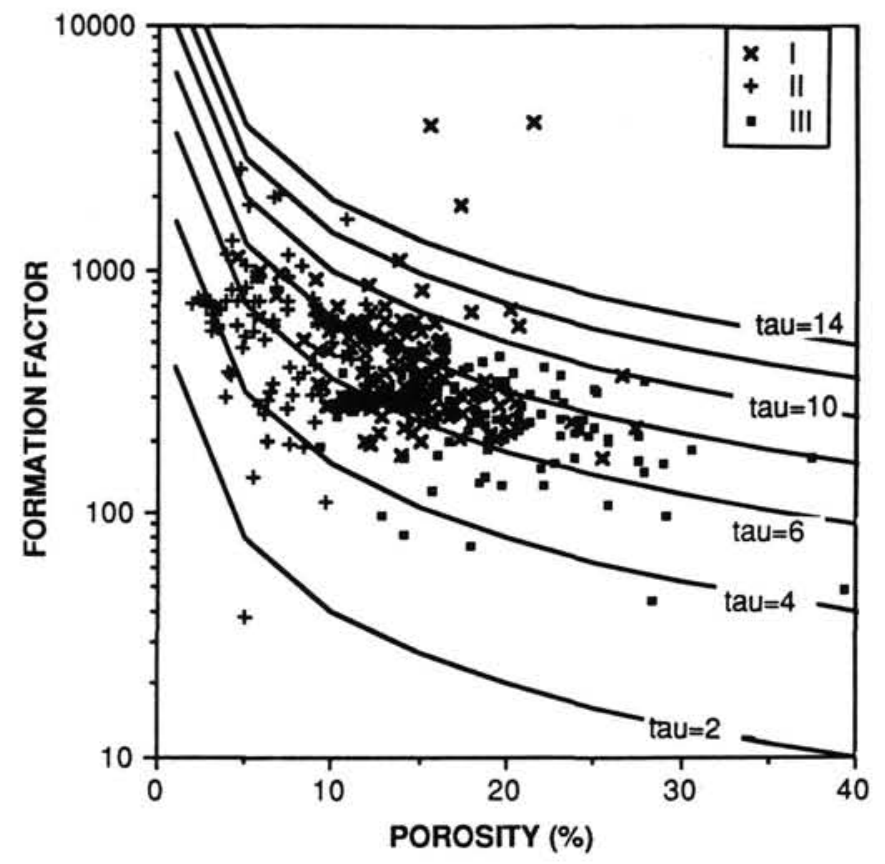

Figure 8. Porosity vs. formation factor with lines of constant tortuosity. Lower-porosity samples tend to have lower tortuosities. Behavior groups as in Figure 6.

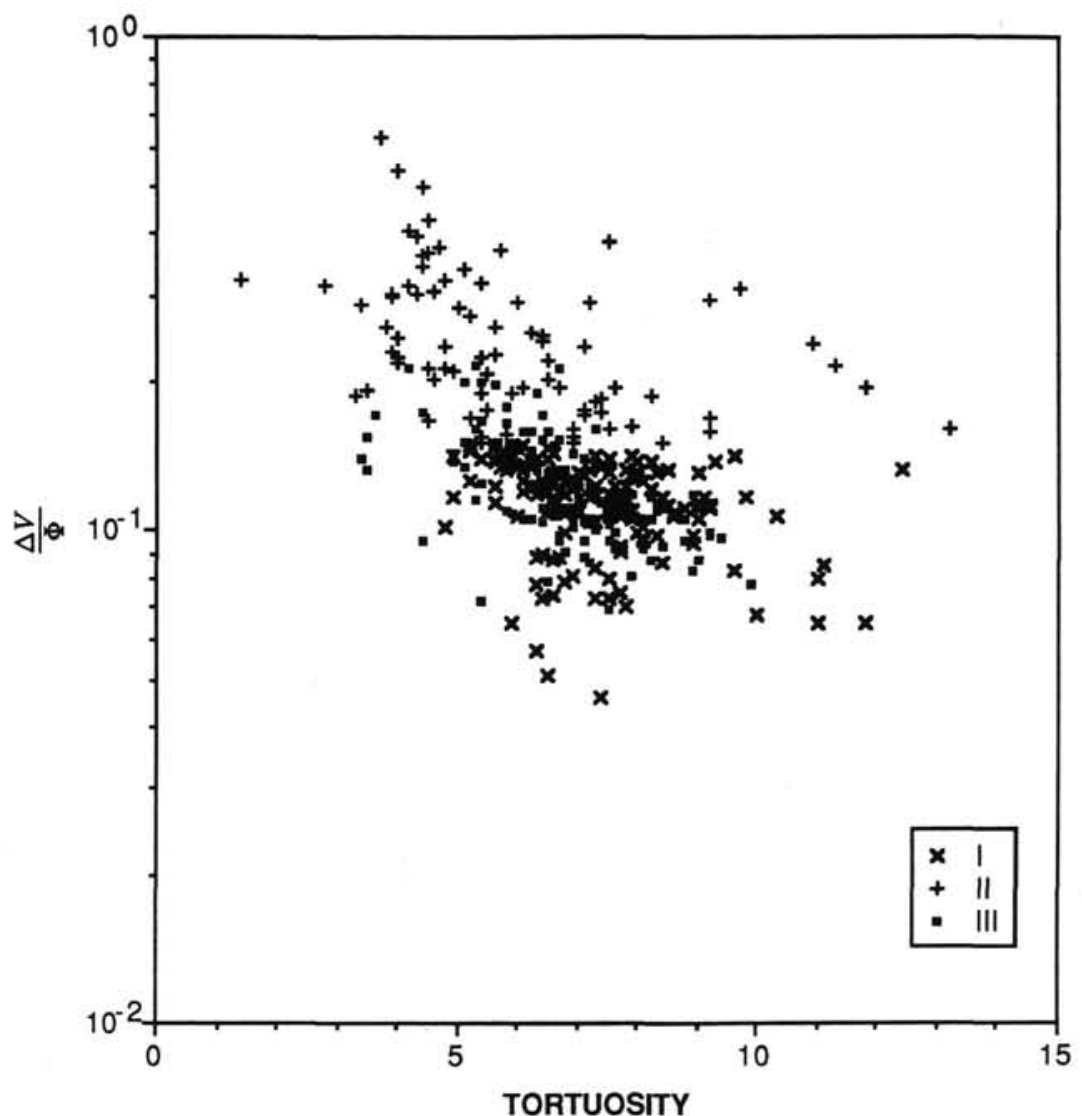

Figure 9. Tortuosity vs. $\Delta V / \Phi$ and basalt type. There is a general trend toward increasing $\Delta \mathrm{V} / \Phi$ with decreasing tortuosity. Behavior groups as in Figure 6. 
as well as leading to better estimates of other properties that are dependent on many of the same parameters as velocity and resistivity. In particular, we have shown that the units seen at Hole 418A have properties that can be explained in light of theoretical and laboratory data from the literature. Most interesting is the relationship between geometrical factors that affect both velocity and electrical resistivity. This relationship suggests that the inclusion of more data holds promise in achieving a classification system for oceanic crustal well logs which may eventually be the equivalent of practices currently used in industry in identifying sedimentary units without recourse to continuous coring.

\section{ACKNOWLEDGMENTS}

This work was partially supported by NSF Grant No. OCE-8408761, the Full Waveform Acoustic Logging Consortium of the Earth Resources Laboratory, MIT, and the Undergraduate Research Opportunities Program, MIT. The authors wish to thank Matthew Salisbury, James Scott, Cristina Broglia, and two anonymous reviewers for critically reading the manuscript.

\section{REFERENCES}

Archie, G. E., 1942. The electrical resistivity logs as an aid in determining reservoir characteristics. J. Pet. Technol., 5:1-8.

Birch, F., 1960. The velocity of compressional waves in rocks to 10 kilobars, 1. J. Geophys. Res., 65:1083-1102.

Bradshaw, A. L., and Schleicher, K. E., 1980. Electrical conductivity of seawater. IEEE J. Ocean. Eng., OE-5:50-62.

Cann, J. R., and Von Herzen, R. P., 1983. Downhole logging at Deep Sea Drilling Project Sites 501, 504, and 505, near the Costa Rica Rift. In Cann, J. R., Langseth, M. G., Honnorez, J., Von Herzen, R. P., White, S. M., et al., Init. Repts. DSDP, 69: Washington (U.S. Govt. Printing Office), 281-299.

Cheng, C. H., and Toksöz, M. N., 1979. Inversion of seismic velocities for the pore aspect ratio spectrum of a rock. J. Geophys. Res., 84: 7533-7543.

Christensen, N. I., Blair, S. C., Wilkens, R. H., and Salisbury, M. H., 1980. Compressional wave velocities, densities, and porosities of basalts from Holes 417A, 417D, and 418A, Deep Sea Drilling Project
Legs 51-53. In Donnelly, T., Francheteau, J., Bryan, W., Robinson, P., Flower, M., Salisbury, M., et al., Init. Repts. DSDP, 51, 52, 53, Pt. 2: Washington (U.S. Govt. Printing Office), 1467-1471.

Horne, R. A., and Frysinger, G. R., 1963. The effect of pressure on the electrical conductivity of seawater. J. Geophys. Res., 68:1967-1973.

Kirkpatrick, R. J., 1979. The physical state of the oceanic crust: Results of downhole geophysical logging in the Mid-Atlantic Ridge at $23^{\circ}$ N. J. Geophys. Res., 84:178-188.

Kuster, G. T., and Toksöz, M. N., 1974. Velocity and attenuation of seismic waves in two-phase media: Part I. Theoretical formulations. Geophysics, 39:587-606.

Nur, A., and Simmons, G., 1969. The effect of saturation on velocity in low porosity rocks. Earth Planet. Sci. Lett., 7:183-193.

O'Connell, R. J., and Budiansky, B., 1974. Seismic velocities in dry and saturated cracked solids. J. Geophys. Res., 79:5412-5426.

Salisbury, M. H., Christensen, N. I., Becker, K., and Moos, D., 1985 The velocity structure of Layer 2 at Deep Sea Drilling Project Site 504 from logging and laboratory experiments. In Anderson, R. N. Honnorez, J., Becker, K., et al., Init. Repts. DSDP, 83: Washington (U.S. Govt. Printing Office), 529-539.

Salisbury, M. H., Scott, J. H., et al., 1986. Proc. ODP, Init. Repts., 102: College Station, TX (Ocean Drilling Program).

Serra, O., 1984. Fundamentals of Well-Log Interpretation: 1. The Acquisition of Logging Data: New York (Elsevier).

Shipboard Scientific Party, 1986. Site 418: Bermuda Rise. In Salisbury, M. H., Scott, J. H., et al., Proc. ODP, Init. Repts., 102: College Station, TX (Ocean Drilling Program), 95-150.

Ward, S. H., and Fraser, D. C., 1967. Conduction of electricity in rocks. In Mining Geophysics (Vol. 2): Tulsa, OK (Society of Exploration Geophysicists), 198-235.

Wilkens, R. H., Simmmons, G., Wissler, T. M., and Caruso, L., 1986. The physical properties of a set of sandstones. Part III. The effects of fine-grained pore-filling material on compressional wave velocity. Int. J. Rock Mech. Min. Sci. Geomech. Abstr., 23(6):313-326.

Wyllie, M.R.J., Gregory, A. R., and Gardner, G.H.F., 1958. An experimental investigation of factors affecting elastic wave velocities in porous media. Geophysics, 23:459-493.

Date of initial receipt: 6 February 1987

Date of acceptance: 9 July 1987

Ms 102B-119 